BMJ Open

Diabetes

Research

\& Care

\title{
The changing landscape of diabetes prevalence among first-generation Asian immigrants in California from 2003 to 2013
}

\author{
Wenjun Fan, ${ }^{1}$ Debora H Lee, ${ }^{1}$ John Billimek, ${ }^{2}$ Sarah Choi, ${ }^{3}$ Ping H Wang ${ }^{1}$
}

To cite: Fan W, Lee $\mathrm{DH}$ Billimek J, et al. The changing landscape of diabetes prevalence among first-generation Asian immigrants in California from 2003 to 2013. BMJ Open Diabetes Research and Care 2017:4:e000327. doi:10.1136/bmjdrc-2016000327

Received 20 September 2016 Revised 21 December 2016 Accepted 26 December 2016

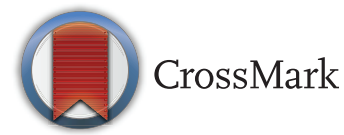

${ }^{1}$ Department of Medicine, UC Irvine Diabetes Center, School of Medicine, University of California, Irvine, California, USA ${ }^{2}$ Health Policy Research Institute, School of Nursing, University of California, Irvine, California, USA ${ }^{3}$ UCLA, School of Nursing, Los Angeles, California, USA

Correspondence to Dr Ping $\mathrm{H}$ Wang; phwang@uci.edu

\section{ABSTRACT}

Objective: The prevalence of diabetes mellitus (DM) is increasing rapidly, particularly in Asia. Asian immigrants in Western countries are a fast-growing population who carry both intrinsic risks due to their genetic background and extrinsic risks associated with Western lifestyles. However, recent trends in diabetes prevalence and associated risk factors among Asian immigrants in the USA are not well understood.

Research design and methods: We examined adults aged 18 and older from the recent California Health Interview Survey data sets from 2003 to 2013 to determine prevalence of known DM among firstgeneration Asian immigrants and whites. The impact of various DM risk factors in Asian immigrants relative to whites was analyzed and multivariable regression models were constructed to obtain adjusted DM risk in Asian immigrants versus in whites.

Results: Across the study span, we identified 2007 first-generation Asian immigrants and 14668 whites as having known DM or prediabetes mellitus (pre-DM). From 2003 to 2013, the prevalence of DM and pre-DM combined rose from $6.8 \%$ to $12.4 \%$ in Asian immigrants and $5.5 \%$ to $6.9 \%$ in whites. Much of the increase could be attributed to pre-DM, which rose from $0.7 \%$ to $3.2 \%$ in Asian immigrants during the study period. The impacts of age and body mass index on DM risk were consistently greater in Asian immigrants than in whites. Non-DM Asian immigrants were found less likely to engage in physical activity than were non-DM whites. After adjustment of various associated factors, Asian immigrants were more likely than whites to have DM and this relative risk for DM gradually increased across the study period.

Conclusions: A rising prevalence of known DM and particularly pre-DM among Asian immigrants in California was observed during the previous decade. To reduce the burden of diabetes and its complications, future strategies should consider specific risk factors for this ethnic group, including encouraging physical activity.

\section{INTRODUCTION}

The prevalence of diabetes mellitus (DM) is increasing at an alarming rate across the

\section{Key messages}

What is already known about this subject?

- Asian immigrants in Western countries are a fast-growing population who carry risks due to their genetic background and Western lifestyles.

What are the new findings?

- Our study shows that first-generation Asian immigrants have an elevated and ever-increasing prevalence of known DM, particularly of prediabetes mellitus, and that non-DM Asian immigrants are notably less engaged in exercise than non-DM whites.

How might these results change the focus of research or clinical practice?

- To reduce the increased burden of diabetes and its complications among Asian immigrants, future intervention strategies should emphasize culturally sensitive recommendations and consider risk factors, including physical activity, specific for this ethnic group.

globe. According to WHO, the global prevalence of DM among adults has risen from $4.7 \%$ in 1980 to $8.5 \%$ in $2014 .{ }^{1}$ In addition to the current 415 million adults living with DM, 318 million adults are now estimated to have impaired glucose tolerance, putting them at high risk of developing DM in the future. ${ }^{2}$ The economic burden is also substantial, with the direct annual cost of DM to the world totaling more than $\$ 827$ billion in 2012. ${ }^{3}$ DM is a global crisis and identifying vulnerable populations and their risk factors is crucial in developing effective strategies to manage the DM epidemic.

Now accounting for $60 \%$ of the world's total as well as diabetic population, Asia lies at the heart of the DM epidemic. ${ }^{45}$ Factors contributing to the DM prevalence among Asians include abdominal obesity, heavy alcohol use and smoking, diet high in refined carbohydrates, and physical inactivity. Notably, interactions between Westernized lifestyles and the 
genetic background of Asians may also promote the growth of DM in this population. ${ }^{5}$ However, few studies have investigated DM among the population of first-generation Asian immigrants residing in Western countries. These reports focus mainly on immigrant populations in Canada and Australia, ${ }^{6-9}$ or those of South Asian ancestry. ${ }^{10}$

Asian immigrants in the USA are a specific significant population because of their potential to impact the DM landscape. Asians currently represent the fastest-growing ethnic group in the USA, with a growth rate of over four times that of the total population. ${ }^{11}$ Furthermore, Asian Americans are $~ 30-60 \%$ more likely to have type $2 \mathrm{DM}$ than their white counterparts. ${ }^{12}$ Their rapidly growing population and increased DM risk positions the Asian immigrant population to be a key target in managing the DM epidemic. As the state with the largest population of Asian immigrants, ${ }^{11}$ California provides an ideal setting to investigate the impact of Asian immigrants on the DM epidemic. In this study, we analyzed the prevalence and trends of DM and prediabetes mellitus (pre-DM) in first-generation Asian immigrants and whites in California from 2003 to 2013, and determined whether Asian immigrants were more likely to have DM after adjusting for confounding factors.

\section{RESEARCH DESIGN AND METHODS}

\section{Study population, data source, and definitions}

The nation's largest state health survey, the California Health Interview Survey (CHIS), is a random-digit dial telephone survey on households in California. The CHIS has been conducted biennially since 2001, collecting information on health conditions, health-related behaviors, insurance coverage, access to services, and other health-related topics. To accurately represent the non-institutionalized population in California, the survey uses proper weighting and variance procedures that adjust for the probability of sampling and reduce the variance of the estimates. Using the six most recent CHIS data sets (2003, 2005, 2007, 2009, 2011, and 2013), we examined adults aged 18 years and older in California to determine the prevalence of DM and associated risk factors among first-generation Asian immigrants compared with whites. Risk factors were selected among the variables collected by the CHIS.

Data taken from the CHIS standardized questionnaire included diabetes status, age, race/ethnicity, sex, body mass index (BMI), education attainment, income level, length of residency in the USA, English proficiency, insurance status in the past year, access to routine medical care, current smoking status, use of blood pressure medications, history of heart failure, vegetable consumption more than seven times per week, and physical activity. We considered participants to have known DM if they had ever been 'told by a doctor that they had diabetes or sugar diabetes' and to have pre-DM if told they had 'borderline or pre-DM'. An additional category for
'DM and pre-DM' was created to include all participants with known DM or pre-DM. We identified Asian immigrants as those who self-reported as Asian and were born outside the USA, and whites as those who self-reported as white and were born in the USA. Physical activity was defined as having engaged in 'hard/vigorous exercise in the past 7 days'.

We further categorized BMI data based on recommended cut-off points for each population group: BMI $<25.0 \mathrm{~kg} / \mathrm{m}^{2}, \quad 25.0-29.9 \mathrm{~kg} / \mathrm{m}^{2}, \quad \geq 30.0 \mathrm{~kg} / \mathrm{m}^{2}$ for whites, and BMI $<23.0 \mathrm{~kg} / \mathrm{m}^{2}, \quad 23.0-27.4 \mathrm{~kg} / \mathrm{m}^{2}$, $\geq 27.5 \mathrm{~kg} / \mathrm{m}^{2}$ for Asians were classified as underweight/ normal weight, overweight, obese, respectively. ${ }^{13}$ BMI categories for overweight and obesity were analyzed relative to the underweight/normal weight category. Education attainment data was categorized into Bachelor's degree or above versus below. Income level was categorized into high income and low income, based on household income relative to the 100-199\% federal poverty line (FPL): household incomes below $100 \%$ FPL and above 300\% FPL were classified as low income and high income, respectively. Length of residency in the US data was categorized into lived in the USA $>15$ vs $\leq 15$ years.

To compare the adjusted ORs (AOR) of DM in Asian immigrants over the study period, we selected factors that were available for all six data sets: age, male sex, BMI, education attainment, health insurance, income level, English proficiency, routine medical care, smoking, vegetable consumption, blood pressure medications, and heart failure. Variables for which data were not available in all six data sets like physical activity data which were only available in the 2005, 2007, and 2009 data sets, were excluded from the multivariable logistic regression models.

\section{Statistical analysis}

All analyses accounted for the complex sampling designs and weights that were developed by the CHIS to represent the California adult population. The characteristics of Asian immigrants versus whites were compared within each yearly data set, with $\chi^{2}$ tests used for categorical variables and t-tests used for continuous variables. The rates of DM prevalence were adjusted for age and sex using 2000 US Census data as the standard for the 2003, 2005, 2007, 2009 CHIS data sets, and 2010 US Census data as the standard for the 2011 and 2013 CHIS data sets. Logistic regression analyses were performed on the factors that could potentially be associated with the development of DM. Multivariable logistic regression models were constructed to obtain AORs of DM risk in Asian immigrants compared with whites for each data set. Model 1 adjusted for variability in age and sex distribution for each group; model 2 additionally adjusted for body weight, a wellrecognized risk factor of $\mathrm{DM}$; model 3 additionally adjusted for factors that were found to be significantly associated with DM in most data sets to ensure that they did not confound the DM risk analyses. These variables 
included education level, insurance status, and use of blood pressure medications. Stata V.12.0 (College Station, Texas, USA) was used for analysis and computation of weighted estimates for projection to the California population. Continuous data were presented as weighted means and SEs, while categorical data were presented as counts or percentages. AORs were presented with $95 \%$ CIs and statistical significance was defined as a $p$ value $<0.05$. This study has been reviewed and approved by the UC Irvine Institutional Review Board.

\section{RESULTS}

\section{Characteristics of study participants}

In general, whites represented the majority of the population in this survey, though the proportion of whites relative to Asian immigrants steadily decreased during the study period. Across the six CHIS data sets, a total of 2007 firstgeneration Asian immigrant participants and 14668 white participants were identified as having either DM or pre-DM. As seen in table 1, Asian immigrants were found to be significantly younger than whites in each of the six data sets, with Asians averaging 44.4 years versus whites 48.3 years in $2003(\mathrm{p}<0.01)$, and this trend continuing through the study period, with Asians averaging 44.7 years versus whites averaging 47.5 years in 2013 ( $p<0.01)$. With regard to BMI, Asian immigrants tended to have a greater number of individuals in the overweight category while whites had more individuals in the obese category.

The proportion of Asian immigrants who were low income was generally two to three times greater than that of whites: $17.2 \%$ of Asian immigrants versus $5.4 \%$ of whites were low income in 2003, and $13.2 \%$ of Asian immigrants versus $7.4 \%$ of whites were low income in 2013. Despite their financial disadvantage, however, Asian immigrants were well educated. Consistently across the study period, at least 70\% spoke fluent English and furthermore, Asian immigrants were significantly more likely than whites to have attained a Bachelor's degree or above, with rates ranging from $50.4 \%$ to $57.4 \%$ in Asian immigrants versus $38.9 \%$ to $43.4 \%$ in whites over the 2003-2013 span.

Across the study period, Asian immigrants were less likely than whites to have health insurance and routine medical care, though $>80 \%$ of Asian immigrants were found to have health insurance and routine medical care in nearly all data sets. Despite less access to healthcare, Asian immigrants had better general health. Compared with whites, Asian immigrants were less likely to smoke, take blood pressure medications, or have heart failure in nearly all six data sets, though vegetable consumption patterns were similar between the two groups. However, Asian immigrants were less engaged in physical activity than were whites, and this difference was significant in all three data sets for which these data were collected.

\section{DM prevalence from 2003 to 2013}

The age-adjusted and sex-adjusted prevalence of known DM and pre-DM were $6.8 \%, 7.8 \%, 8.4 \%, 8.7 \%, 10.7 \%$,
$12.4 \%$ in first-generation Asian immigrants and $5.5 \%$, $6.0 \%, 6.7 \%, 6.1 \%, 7.3 \%, 6.9 \%$ in whites, in the 2003 , 2005, 2007, 2009, 2011, and 2013 surveys, respectively (figure 1A). During this 10-year period, Asian immigrants consistently had a higher prevalence of DM and pre-DM compared with whites and this gap widened with time, with significant differences appearing by year $2009(8.7 \%$ vs $6.1 \%, \mathrm{p}<0.05)$.

To analyze these trends in further detail, all patients with diabetes were broken down into those with DM and those with pre-DM. Prevalence of DM and pre-DM were then re-evaluated separately. The prevalence of DM among whites increased at a moderate rate $(4.8-5.6 \%$ from 2003 to 2013), compared with the steeper rise seen in Asian immigrants (6.2-10.4\% from 2003 to 2013; figure 1B). This divergence was even more apparent when examining the prevalence of pre-DM alone. The prevalence of pre-DM in the two groups began nearly identically in 2003, but diverged as time progressed, with significant differences appearing by year $2007(2.1 \%$ vs $1.3 \%, \mathrm{p}<0.05)$ and the gap growing to a twofold higher prevalence among Asian immigrants by 2013 (3.2\% vs $1.6 \%, \mathrm{p}<0.01$; figure $1 \mathrm{C}$ ).

\section{Impacts of various factors on DM risk in Asian immigrants versus in whites}

A number of variables emerged in the DM risk factor analyses investigating the impact of various factors on DM risk in first-generation Asian immigrants compared with that in whites, with age and BMI consistently appearing as significant factors (table 2). For Asian immigrants and whites with the same age, Asian immigrants were 1.35 times more likely to have DM in 2003 ( $\mathrm{p}<0.01)$, with this trend continuing into 2013 during which Asian immigrants were 1.97 times more likely to have DM $(p<0.01)$. Likewise, Asian immigrants were 1.35 times more likely than whites with the same BMI to have DM in 2003 $(\mathrm{p}<0.01)$, with this trend continuing into 2013 during which Asian immigrants were 2.17 times more likely to have DM $(\mathrm{p}<0.01)$. Except for age and BMI, other factors either did not significantly impact DM risk in Asian immigrants more so than in whites, or the significance was not consistent across the study period.

In all the three data sets for which the data were collected, unadjusted analyses revealed that Asian immigrants were less likely to engage in physical activity (table 1). Despite this, regression analyses suggested that physical activity level was not significantly different between Asian immigrants with DM and whites with DM (table 2). However, when we performed subgroup analysis by stratifying the participants into two subgroups, $\mathrm{DM}$ and non-DM, Asian immigrants and whites displayed different patterns of physical activity. Notably, non-DM Asian immigrants were less likely to exercise than were non-DM whites, with $24-26 \%$ of non-DM Asian immigrants engaging in physical activity compared with $32-38 \%$ of non-DM whites (figure 2). 
Table 1 Characteristics of survey participants-Asian immigrants versus whites

\begin{tabular}{|c|c|c|c|c|c|c|}
\hline & $\begin{array}{l}2003 \\
\text { Asian/white }\end{array}$ & $\begin{array}{l}2005 \\
\text { Asian/white }\end{array}$ & $\begin{array}{l}2007 \\
\text { Asian/white }\end{array}$ & $\begin{array}{l}2009 \\
\text { Asian/white }\end{array}$ & $\begin{array}{l}2011 \\
\text { Asian/white }\end{array}$ & $\begin{array}{l}2013 \\
\text { Asian/white }\end{array}$ \\
\hline $\begin{array}{l}\text { Participants (\#) (total } \\
\text { population) }\end{array}$ & $\begin{array}{l}3068 / 24269 \\
(2376091 / \\
11933848)\end{array}$ & $\begin{array}{l}3171 / 26565 \\
(2630460 / \\
12309496)\end{array}$ & $\begin{array}{l}3390 / 31388 \\
(2564432 / \\
11934462)\end{array}$ & $\begin{array}{l}3989 / 29133 \\
(2561937 / \\
12092288)\end{array}$ & $\begin{array}{l}3363 / 24148 \\
(2722942 / \\
11282029)\end{array}$ & $\begin{array}{l}1109 / 12654 \\
(2752795 / \\
11325363)\end{array}$ \\
\hline $\begin{array}{l}\text { DM and pre-DM (\#) (DM and } \\
\text { pre-DM population) }\end{array}$ & $\begin{array}{l}214 / 1751 \\
(163933 / \\
778140)\end{array}$ & $\begin{array}{l}254 / 2243 \\
(206987 / \\
888604)\end{array}$ & $\begin{array}{l}353 / 3273 \\
(236438 / \\
978231)\end{array}$ & $\begin{array}{l}490 / 3053 \\
(250408 / \\
904882)\end{array}$ & $\begin{array}{l}532 / 2741 \\
(292674 / \\
997382)\end{array}$ & $\begin{array}{l}164 / 1607 \\
(346889 / \\
958166)\end{array}$ \\
\hline DM (\#) (DM population) & $\begin{array}{l}197 / 1513 \\
(148969 / \\
678380)\end{array}$ & $\begin{array}{l}218 / 1897 \\
(179248 / \\
751951)\end{array}$ & $\begin{array}{l}294 / 2724 \\
(179509 / \\
812382)\end{array}$ & $\begin{array}{l}406 / 2645 \\
(199918 / \\
763855)\end{array}$ & $\begin{array}{l}434 / 2311 \\
(231558 / \\
836081)\end{array}$ & $\begin{array}{l}125 / 1319 \\
(277116 / \\
769668)\end{array}$ \\
\hline $\begin{array}{l}\text { Pre-DM (\#) (pre-DM } \\
\text { population) }\end{array}$ & $\begin{array}{l}17 / 238 \\
(14964 / \\
99760)\end{array}$ & $\begin{array}{l}36 / 346 \\
(27739 / \\
136653)\end{array}$ & $\begin{array}{l}59 / 549 \\
(56929 / \\
165849)\end{array}$ & $\begin{array}{l}84 / 408 \\
(50490 / \\
141027)\end{array}$ & $\begin{array}{l}98 / 430 \\
(61116 / \\
161301)\end{array}$ & $\begin{array}{l}39 / 288 \\
(69773 / \\
188498)\end{array}$ \\
\hline Age (years) & $\begin{array}{l}44.4 \pm 0.3 / 48.3 \\
\pm 0.1^{\star \star}\end{array}$ & $\begin{array}{l}44.9 \pm 0.3 / 48.6 \\
\pm 0.1^{\star \star}\end{array}$ & $\begin{array}{l}46.2 \pm 0.3 / 48.7 \\
\pm 0.1^{\star \star}\end{array}$ & $\begin{array}{l}46.4 \pm 0.5 / 48.5 \\
\pm 0.2^{\star \star}\end{array}$ & $\begin{array}{l}46.7 \pm 0.4 / 50.0 \\
\pm 0.2^{\star \star}\end{array}$ & $\begin{array}{l}44.7 \pm 0.8 / 47.5 \\
\pm 0.3^{\star \star}\end{array}$ \\
\hline Male (\%) & $47.3 / 48.6^{\star}$ & $44.8 / 49.3^{\star *}$ & $46.4 / 49.2^{* *}$ & $47.2 / 49.3^{\star}$ & $45.0 / 49.1^{\star \star}$ & $43.6 / 48.7^{\star \star}$ \\
\hline BMI $\left(\mathrm{kg} / \mathrm{m}^{2}\right)$ & $\begin{array}{l}23.8 \pm 0.1 / 26.2 \\
\pm 0.0^{\star \star}\end{array}$ & $\begin{array}{l}23.7 \pm 0.1 / 26.4 \\
\pm 0.1^{\star \star}\end{array}$ & $\begin{array}{l}23.8 \pm 0.1 / 26.5 \\
\pm 0.1^{\star \star}\end{array}$ & $\begin{array}{l}23.7 \pm 0.1 / 26.6 \\
\pm 0.1^{\star \star}\end{array}$ & $\begin{array}{l}24.3 \pm 0.1 / 26.8 \\
\pm 0.1^{\star \star}\end{array}$ & $\begin{array}{l}24.7 \pm 0.2 / 26.7 \\
\pm 0.1^{\star \star}\end{array}$ \\
\hline Overweight (\%) & $39.3 / 35.5$ & $39.5 / 34.4$ & $41.7 / 34.7^{\star \star}$ & $37.6 / 33.8$ & $40.9 / 34.9^{\star}$ & $42.8 / 34.6^{\star}$ \\
\hline Obesity (\%) & $13.0 / 18.9^{\star \star}$ & $12.0 / 20.3^{\star *}$ & $12.5 / 21.1^{\star \star}$ & $13.6 / 21.8^{\star *}$ & $16.1 / 22.6^{\star \star}$ & $19.4 / 21.7$ \\
\hline $\begin{array}{l}\text { Bachelor's degree or } \\
\text { above (\%) }\end{array}$ & $50.4 / 38.9^{\star *}$ & $53.1 / 39.9^{* *}$ & $53.1 / 40.0^{* *}$ & $57.4 / 41.6^{\star *}$ & $55.8 / 43.4^{\star *}$ & $56.5 / 42.4^{\star *}$ \\
\hline High income (\%) & $51.0 / 68.6^{\star *}$ & $54.9 / 71.5^{\star *}$ & $54.9 / 71.7^{\star *}$ & $54.1 / 68.9^{* *}$ & $52.2 / 66.4^{\star *}$ & $53.6 / 66.2$ \\
\hline Low income (\%) & $17.2 / 5.4^{\star \star}$ & $13.1 / 4.8^{\star *}$ & $14.4 / 5.3^{\star \star}$ & $12.6 / 6.4$ & $14.3 / 7.7^{* *}$ & $13.2 / 7.4$ \\
\hline Lived in USA >15 years (\%) & $53.2 /-$ & $59.5 /-$ & $62.4 /-$ & $64.2 /-$ & 63.8/- & 63.2/- \\
\hline English proficiency (\%) & $71.6 / 99.9^{\star *}$ & $70.2 / 100.0^{\star *}$ & $73.1 / 99.9^{\star *}$ & $72.8 / 100.0^{\star \star}$ & $72.4 / 99.9^{* \star}$ & $74.6 / 99.9^{\star \star}$ \\
\hline Health insurance (\%) & $81.0 / 87.2^{\star \star}$ & $79.5 / 88.2^{* \star}$ & $81.8 / 88.1^{\star \star}$ & $82.5 / 85.7$ & $81.0 / 86.4^{\star \star}$ & $81.2 / 86.4^{\star}$ \\
\hline Routine medical care (\%) & $86.6 / 88.0^{\star \star}$ & $87.8 / 90.9^{\star \star}$ & $-/-$ & $83.3 / 88.9^{\star \star}$ & $83.0 / 88.7^{\star \star}$ & $83.9 / 89.0^{\star \star}$ \\
\hline Smoking (\%) & $13.4 / 17.3^{\star *}$ & $10.7 / 16.3^{\star *}$ & $11.0 / 15.0^{* *}$ & $10.4 / 14.2^{*}$ & $10.2 / 14.9^{\star \star}$ & 10.0/13.6 \\
\hline BP medications (\%) & $16.2 / 18.7^{\star \star}$ & $17.6 / 20.2^{\star \star}$ & $19.1 / 21.2^{\star \star}$ & $20.3 / 20.3^{\star *}$ & $19.0 / 22.4^{\star \star}$ & $17.9 / 22.6$ \\
\hline Heart failure (\%) & $0.8 / 1.5^{\star \star}$ & $1.1 / 2.0^{\star \star}$ & $1.4 / 2.1^{\star \star}$ & $0.6 / 1.9$ & $1.8 / 2.2^{\star \star}$ & $0.5 / 2.3^{*}$ \\
\hline Vegetable consumption (\%) & $-1-$ & $46.6 / 46.7$ & $62.0 / 61.0$ & $56.5 / 56.7$ & $57.0 / 59.5$ & $-1-$ \\
\hline Physical activity (\%) & $-1-$ & $23.9 / 30.6^{\star *}$ & $25.5 / 36.2^{\star \star}$ & $26.0 / 34.7^{\star \star}$ & $-1-$ & $-1-$ \\
\hline
\end{tabular}

Continuous data were presented as weighted means \pm SE, categorical data were presented as counts or percentages; data that were not available in the given data set was marked with '-'.

Data in parenthesis were estimated populations calculated based off weighted procedures developed by the CHIS.

Analyses were conducted using t-test for continuous variables and $\chi^{2}$ test for categorical variables; ${ }^{*} p<0.05,{ }^{* *} p<0.01$ between Asian immigrants and whites within the same yearly data set.

$\mathrm{BMI}$, body mass index; BP, blood pressure; DM, diabetes mellitus; pre-DM, prediabetes mellitus.

\section{Adjusted risk of DM in Asian immigrants}

After adjusting for potential confounding risk factors using multivariable logistic regression analyses, the AOR of $\mathrm{DM}$ was found to be higher in first-generation Asian immigrants than in whites for all three models. With model 1 , the AORs of DM in Asian immigrants were 36-103\% higher compared with whites. With model 2, the AORs of DM in Asian immigrants were $75-162 \%$ higher than in whites. With model 3, the AORs of DM in Asian immigrants were $61-220 \%$ higher than in whites, and logged its highest record in 2013 (AOR 3.20; 95\% CI 1.90 to 5.38). All three models showed higher and rising relative likelihoods for DM among Asian immigrants compared with whites during the study span from 2003 to 2013 (table 3).

\section{CONCLUSIONS}

Our study showed that DM prevalence in California has been increasing over the past decade, particularly among the first-generation Asian immigrant population. From 2003 to 2013, rates of known DM rose from 5.5\% to $6.9 \%$ among whites, while rates rose from $6.8 \%$ to $12.4 \%$ among Asian immigrants. Furthermore, the number of Asian immigrants affected by DM grew from 163933 to 346339 during the study period. Our findings coincide with the global upward trend in DM prevalence, a trend that has grown particularly significant in Asia. DM now affects a total of 109.6 million in China and 69.2 million in India alone. ${ }^{2}$ However, the massive influence of the Asian DM epidemic continues to expand as people traverse national borders and migrate to Western countries. Asians are the fastest growing minority ethnic group in the USA, accounting for $4.8 \%$ of the total population in 2010 and a projected $9.3 \%$ by $2060 .{ }^{14}$ The growth of the Asian immigrant population and its increase in DM prevalence collectively renders it a significant population that must be addressed to manage the DM epidemic. 


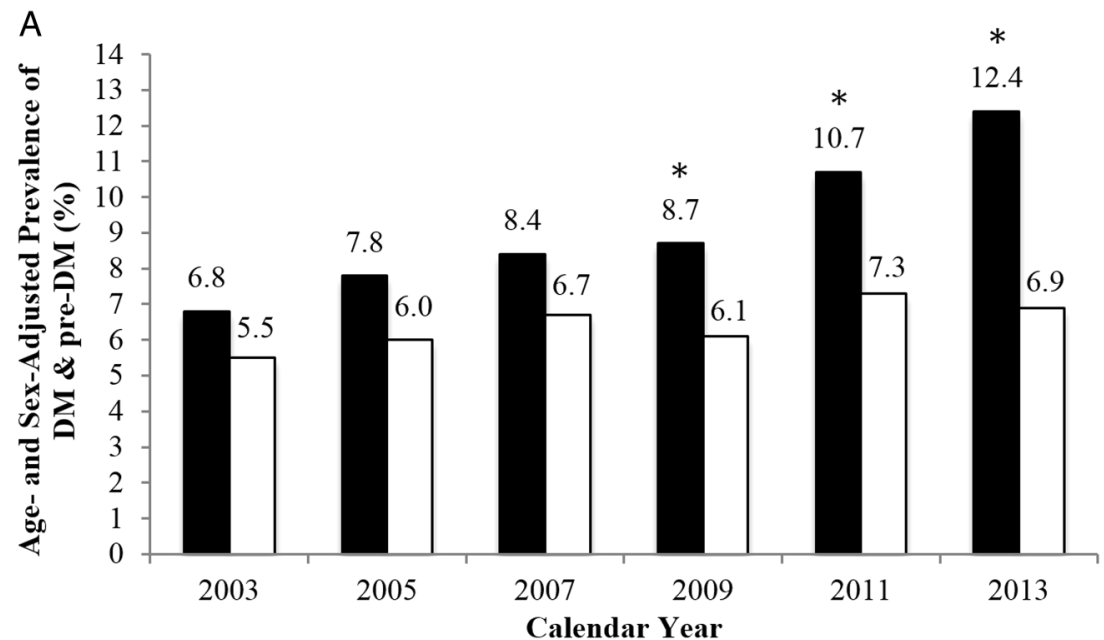


Table 2 Impacts of various factors on DM risk in Asian immigrants versus in whites

\begin{tabular}{|c|c|c|c|c|c|c|}
\hline & 2003 & 2005 & 2007 & 2009 & 2011 & 2013 \\
\hline Age & $1.35^{\star \star}(1.08$ to 1.69$)$ & $1.37^{\star *}(1.08$ to 1.73$)$ & $1.35^{\star \star}(1.13$ to 1.60$)$ & $1.59^{\star *}(1.21$ to 2.07$)$ & $1.59^{\star *}(1.34$ to 1.89$)$ & $1.97^{\star \star}$ (1.44 to 2.71$)$ \\
\hline Male & $1.07(0.86$ to 1.32$)$ & $1.11(0.88$ to 1.40$)$ & $1.14(0.97$ to 1.35$)$ & $1.34^{*}(1.05$ to 1.72$)$ & $1.25^{*}(1.05$ to 1.49$)$ & $1.58^{\star \star}$ (1.17 to 2.11$)$ \\
\hline BMI & $1.35^{\star \star}(1.08$ to 1.68$)$ & $1.58^{\star *}(1.23$ to 2.03$)$ & $1.70^{\star \star}(1.42$ to 2.05$)$ & $2.08^{\star *}(1.62$ to 2.67$)$ & $1.81^{\star \star}(1.49$ to 2.21$)$ & $2.17^{\star *}(1.57$ to 3.00$)$ \\
\hline Overweight & $1.28(0.10$ to 1.66$)$ & $1.37^{\star}(1.01$ to 1.85$)$ & $1.37^{\star *}(1.12$ to 1.67$)$ & $1.71^{\star *}(1.29$ to 2.28$)$ & $1.50^{\star \star}(1.23$ to 1.83$)$ & $1.77^{\star \star}$ ( 1.23 to 2.55$)$ \\
\hline Obese & $1.04(0.80$ to 1.34$)$ & 1.25 (0.88 to 1.79$)$ & $1.16(0.91$ to 1.48$)$ & 1.36 (0.99 to 1.86$)$ & $1.28(0.97$ to 1.67$)$ & $1.65^{*}$ (1.06 to 2.57$)$ \\
\hline $\begin{array}{l}\text { Bachelor's degree or } \\
\text { above }\end{array}$ & 1.12 (0.91 to 1.38$)$ & 1.18 (0.94 to 1.48$)$ & $1.20^{*}(1.02$ to 1.43$)$ & $1.46^{\star *}(1.13$ to 1.89$)$ & $1.31^{\star \star}(1.10$ to 1.57$)$ & $1.64^{\star *}(1.22$ to 2.19$)$ \\
\hline High income & $1.08(0.84$ to 1.39$)$ & $1.02(0.82$ to 1.28$)$ & 1.02 (0.82 to 1.27$)$ & $1.42^{*}(1.07$ to 1.87$)$ & $1.20(0.96$ to 1.51$)$ & 1.33 (0.96 to 1.83$)$ \\
\hline Low income & $1.00(0.71$ to 1.40$)$ & $1.04(0.71$ to 1.52$)$ & $0.96(0.70$ to 1.31$)$ & 1.25 (0.75 to 2.09$)$ & $1.20(0.88$ to 1.67$)$ & $1.33(0.74$ to 2.42$)$ \\
\hline English proficiency & $0.93(0.72$ to 1.19$)$ & $0.96(0.72$ to 1.27$)$ & 1.08 (0.87 to 1.35$)$ & 1.11 (0.87 to 1.43 ) & $0.98(0.80$ to 1.20$)$ & $1.51^{*}(1.06$ to 2.14$)$ \\
\hline Health insurance & 1.10 (0.89 to 1.36$)$ & 1.15 (0.91 to 1.44$)$ & $1.19^{*}(1.00$ to 1.40$)$ & $1.37^{\star}(1.06$ to 1.77$)$ & $1.28^{\star \star}(1.07$ to 1.52$)$ & $1.61^{\star \star}(1.20$ to 2.17$)$ \\
\hline Routine medical care & $1.08(0.87$ to 1.34$)$ & $1.12(0.89$ to 1.41$)$ & - & $1.41^{* *}(1.09$ to 1.82$)$ & $1.30^{\star *}(1.09$ to 1.54$)$ & $1.64^{\star *}$ (1.22 to 2.20$)$ \\
\hline Smoking & $1.04(0.83$ to 1.29$)$ & $1.10(0.87$ to 1.37$)$ & $1.13(0.96$ to 1.34$)$ & $1.33^{*}(1.04$ to 1.71$)$ & $1.22^{*}(1.03$ to 1.46$)$ & $1.56^{* \star}(1.17$ to 2.10$)$ \\
\hline BP medications & 1.31 (0.99 to 1.74$)$ & 1.18 (0.93 to 1.51$)$ & $1.26^{*}(1.01$ to 1.57$)$ & $1.37^{*}(1.00$ to 1.87$)$ & $1.46^{\star *}(1.15$ to 1.85$)$ & $1.83^{\star *}(1.20$ to 2.79$)$ \\
\hline Heart failure & $1.89(0.86$ to 4.17$)$ & - & $1.27(0.87$ to 1.86$)$ & $1.40(0.77$ to 2.54$)$ & 1.46 (0.88 to 2.12$)$ & $1.14(0.51$ to 2.55$)$ \\
\hline $\begin{array}{l}\text { Vegetable } \\
\text { consumption }\end{array}$ & - & 1.10 (0.87 to 1.38$)$ & 1.14 (0.96 to 1.34$)$ & $1.34^{*}(1.05$ to 1.72$)$ & $1.24^{*}(1.04$ to 1.48$)$ & - \\
\hline Physical activity & - & 1.04 (0.83 to 1.31$)$ & 1.04 (0.88 to 1.23 ) & 1.26 (0.97 to 1.64$)$ & - & - \\
\hline
\end{tabular}

Data were presented as adjusted OR $(95 \% \mathrm{Cl})$; data that were not available in the given data set was marked with ' - '.

Analyses were conducted using multivariable regression, ${ }^{*} p<0.05,{ }^{* *} p<0.01$.

$\mathrm{BMI}$, body mass index; BP, blood pressure; DM, diabetes mellitus.

Asian immigrants have an elevated prevalence of DM that has been increasing steeply over the past decade; more alarmingly however, much of this increase can be attributed to the rise in pre-DM. In our analysis, while the prevalence of DM among Asian immigrants nearly doubled during the study period, the prevalence of pre-DM more than quadrupled, from $0.7 \%$ to $3.2 \%$. Pre-DM, identified as either impaired fasting glucose or impaired glucose tolerance, is a metabolic condition characterized by a blood glucose concentration higher than normal, but lower than the threshold for DM. Individuals with pre-DM are at increased risk of DM as well as its complications, such as nephropathy, neuropathy, retinopathy, and macrovascular disease. ${ }^{15}$ About $5-10 \%$ of patients with pre-DM will develop DM every year, ${ }^{16} 30 \%$ will develop DM over 4 years, and up to $70 \%$ of those with pre-DM will eventually develop DM. ${ }^{17} 18$ Though hyperglycemia and insulin resistance seem to be the main mechanisms driving the progression of pre-DM, further categorization to identify the individual pathophysiological mechanisms may be more useful in predicting risk, preventing diabetes, and treating its complications. ${ }^{19}$ To prevent pre-DM from progressing into full-blown diabetes, current medical guidelines recommend lifestyle changes, like weight loss, dietary change, and physical activity. ${ }^{15}$

Though managing the issue of increasing DM prevalence among Asian immigrants is a complex matter, our study presents one possible consideration: physical activity. In our study, Asian immigrants were less likely to exercise than whites. Curiously, while rates of physical activity were similar among those with DM, non-DM Asian immigrants were less engaged in exercise than were non-DM whites. While a causal relationship cannot be established with our analysis, the data suggest that non-DM Asian immigrants' lower physical activity levels could be associated with their increased risk of developing DM. Further studies should investigate whether increased physical activity among non-DM Asian immigrants can lead to decreased DM in the future. Our findings also showed that when Asian immigrants develop DM, however, an increased motivation to exercise may have allowed them to match their white counterparts with regard to physical activity. Sedentary lifestyle is a well-known risk factor of diabetes, ${ }^{20-22}$ and physical activity is an important measure in its prevention and management. However, studies have shown that immigrants are less likely to participate in physical activity, ${ }^{23-25}$ hindered by constraints including personal motivations, language barriers, socioeconomic factors, and psychological trauma relating to migration. ${ }^{26}$ Immigrants who do engage in physical activity, however, are more likely to participate in more conventional forms of exercise, like home-based exercise, aerobics, and weight training. ${ }^{27}$ Public health recommendations should emphasize culturally sensitive promotion of physical activity in interventions for DM development among Asian immigrants, particularly in non-DM individuals at risk of progressing to DM.

Our study shows that after adjustment of various confounding factors, first-generation Asian immigrants were more likely than whites to have DM. This finding was consistent across all three models, with the DM risk in Asian immigrants gradually increasing across the study period. Asian immigrants residing in Western countries are a unique population who carry both intrinsic risks due to their genetic background and extrinsic risks associated with Western lifestyles. Previous studies in Canada and Australia have investigated DM risk in Asian immigrants versus native-born individuals. Others have reported that South Asian immigrants in Canada were more likely than native-born Canadians to have DM. ${ }^{728}$ Similarly, Asian immigrants in Australia were found to be 


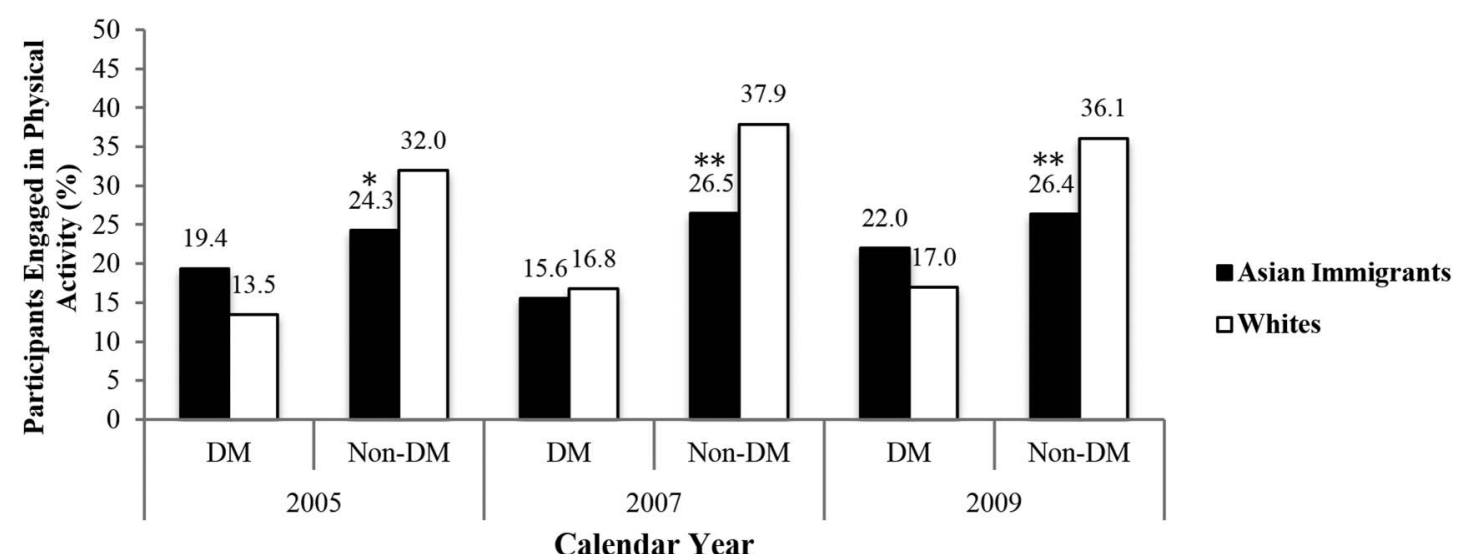

Figure 2 Subgroup analysis of physical activity rates-Asian immigrants versus whites stratified by DM status. Data were presented as weighted percentages of Asian immigrants or whites within each of the DM and non-DM groups. DM groups included participants affected by any form of DM, including DM and pre-DM; non-DM groups included participants unaffected by any form of DM. The $p$ values were calculated within each group by comparing the weighted percentages of Asian immigrants versus whites. ${ }^{*} p<0.05,{ }^{*} p<0.01$. DM, diabetes mellitus.

at increased DM risk compared with native-born Australians, though the difference became significant only when the immigrants' duration of residence was 20 years or greater. $^{8}$ The DM risk in Asian immigrants may be explained in part by immigrant status; however, intrinsic factors may contribute as well. One Canadian study found that South Asian immigrants had higher odds of DM than white immigrants, suggesting an interaction between race and DM. ${ }^{6}$ To effectively manage the DM epidemic in Asian immigrants, the issue of increased DM risk among Asian immigrants residing in Western countries should be regarded wholly, considering both genetic predisposition and lifestyle changes.

While our study provides new insight into DM prevalence among Asian immigrants, there are some limitations. First, we cannot rule out the possibility of reporting bias associated with a population health survey as low response rates, question ambiguity, and selfreported data can influence the validity of studies that use self-reported data. However, our calculated DM prevalence among whites (5.6\% in 2013) was comparable to data previously reported by the Centers for
Disease Control and Prevention (CDC; 6.0\% in 2013), suggesting that the validity of our data set is comparable with other data sets. ${ }^{29}$ The survey-based data set also limited the screening of DM to participants with known DM and could not account for undiagnosed individuals. Better screening to include these patients could have resulted in a higher actual prevalence of DM than that reported in our study. Second, the data sets for 2011 and 2013 were weighted based on the 2010 Census, while the data sets for 2009 and earlier were weighted based on the 2000 Census. As a result, it was not possible to merge all six data sets together to calculate the prevalence change over the entire study period. Thus, analyses were conducted within each individual data set and not collectively across the six data sets. Third, due to our study design and the limitations in sample size, we were unable to break down and study DM prevalence and risk factors among individual Asian immigrant subgroups. Specific Asian subgroups such as Filipinos, Japanese, and South Asians are known to have particularly high rates of DM that are often obscured by the large population of Chinese and other Asian subgroups. ${ }^{30-32}$ Future

Table 3 Multivariable logistic regression models of DM risk in Asian immigrants compared with whites

\begin{tabular}{llll}
\hline & Model 1 & Model 2 & Model 3 \\
\hline 2003 & $1.36^{\star *}(1.09$ to 1.70$)$ & $1.78^{\star *}(1.35$ to 2.34$)$ & $1.72^{\star *}(1.24$ to 2.40$)$ \\
2005 & $1.39^{\star *}(1.10$ to 1.76$)$ & $1.82^{\star *}(1.32$ to 2.51$)$ & $1.61^{\star *}(1.13$ to 2.28$)$ \\
2007 & $1.36^{\star *}(1.15$ to 1.61$)$ & $1.75^{\star *}(1.41$ to 2.17$)$ & $1.69^{\star *}(1.25$ to 2.29$)$ \\
2009 & $1.60^{\star *}(1.22$ to 2.09$)$ & $2.15^{\star *}(1.56$ to 2.95$)$ & $1.87^{\star *}(1.33$ to 2.62$)$ \\
2011 & $1.61^{\star *}(1.36$ to 1.91$)$ & $2.04^{\star *}(1.66$ to 2.52$)$ & $1.95^{\star *}(1.43$ to 2.65$)$ \\
2013 & $2.03^{\star *}(1.47$ to 2.79$)$ & $2.62^{\star *}(1.76$ to 3.93$)$ & $3.20^{\star *}(1.90$ to 5.38$)$ \\
\hline
\end{tabular}

Data was presented as adjusted OR $(95 \% \mathrm{Cl})$.

Model 1: adjusted for age (continuous) and sex; model 2: model 1+overweight; model 3: model 2+Bachelor's degree or above +health insurance+BP medications.

Analyses were conducted using multivariable logistic regression, ${ }^{*} \mathrm{p}<0.05,{ }^{* *} \mathrm{p}<0.01$.

$\mathrm{BP}$, blood pressure; DM, diabetes mellitus. 
studies should investigate Asian immigrants across different subgroups as variations in DM prevalence and risk factors may exist within the larger population of Asian immigrants.

In conclusion, there was a rising trend in known diabetes among first-generation Asian immigrants in California during the previous decade and the escalating prevalence of pre-DM is alarming. To reduce the increased burden of diabetes and its complications among this population, future intervention strategies to prevent diabetes should consider risk factors, particularly physical activity, and unique opportunities specific for this ethnic group.

Acknowledgements The authors appreciate the Data Coordinating Center at the California Health Interview Survey (CHIS) for providing access to the CHIS database.

Contributors WF and PHW conceived and designed the study. WF, DHL, JB and SC contributed to statistical modeling and data analysis. WF, DHL, and PHW drafted the manuscript. All authors made critical review and revisions of manuscript. PHW is the guarantor of this work and, as such, had full access to all the data and takes responsibility for the integrity of the data and the accuracy of the data analysis.

Funding This study was supported by UC Irvine Diabetes Center and the Ko Family Foundation.

\section{Competing interests None declared.}

Ethics approval UC Irvine Institutional Review Board.

Provenance and peer review Not commissioned; externally peer reviewed.

Data sharing statement The California Health Interview Survey is conducted biennially by the UCLA Center for Health Policy Research. Researchers can access the publicly available CHIS data files, and customize and run their own data searches using the Public Use Data Files.

Open Access This is an Open Access article distributed in accordance with the Creative Commons Attribution Non Commercial (CC BY-NC 4.0) license, which permits others to distribute, remix, adapt, build upon this work noncommercially, and license their derivative works on different terms, provided the original work is properly cited and the use is non-commercial. See: http:// creativecommons.org/licenses/by-nc/4.0/

\section{REFERENCES}

1. World Health Organization. Global report on diabetes. Geneva: 2016.

2. International Diabetes Federation. IDF Diabetes Atlas. 7th edn. 2015.

3. NCD Risk Factor Collaboration (NCD-RisC). Worldwide trends in diabetes since 1980: a pooled analysis of 751 population-based studies with 4.4 million participants. Lancet 2016;387:1513-30.

4. Population Reference Bureau. 2016 World Population Data Sheet. Washington DC: 2016.

5. Hu FB. Globalization of diabetes: the role of diet, lifestyle, and genes. Diabetes Care 2011;34:1249-57.

6. Veenstra G, Patterson AC. South Asian-white health inequalities in Canada: intersections with gender and immigrant status. Ethn Health 2016;21:639-48.

7. Benchimol EI, Manuel DG, To T, et al. Asthma, type 1 and type 2 diabetes mellitus, and inflammatory bowel disease amongst South Asian Immigrants to Canada and their children: a population-based cohort study. PLoS ONE 2015;10:e0123599.

8. Pasupuleti SSR, Jatrana S, Richardson K. Effect of nativity and duration of residence on chronic health conditions among Asian immigrants in Australia: a longitudinal investigation. J Biosoc Sci 2016;48:322-41.
9. Berkowitz SA, Fabreau GE, Raghavan S, et al. Risk of developing diabetes among refugees and immigrants: a longitudinal analysis. $J$ Community Health 2016;41:1274-81.

10. Kooner JS, Saleheen D, Sim X, et al. Genome-wide association study in individuals of South Asian ancestry identifies six new type 2 diabetes susceptibility loci. Nat Genet 2011;43:984-9.

11. Hoeffel EM, Rastogi S, Kim MO, et al. The Asian Population: 2010. U.S. Census Bureau, 2012.

12. Lee JW, Brancati FL, Yeh HC. Trends in the prevalence of type 2 diabetes in Asians versus whites: results from the United States National Health Interview Survey, 1997-2008. Diabetes Care 2011;34:353-7.

13. WHO Expert Consultation. Appropriate body-mass index for Asian populations and its implications for policy and intervention strategies. Lancet Lond Engl 2004;363:157-63.

14. Shaw JE, Sicree RA, Zimmet PZ. Global estimates of the prevalence of diabetes for 2010 and 2030. Diabetes Res Clin Pract 2010;87:4-14.

15. Tabák AG, Herder C, Rathmann W, et al. Prediabetes: a high-risk state for diabetes development. Lancet Lond Engl 2012;379:2279-90.

16. Mainous AG, Tanner RJ, Baker R, et al. Prevalence of prediabetes in England from 2003 to 2011: population-based, cross-sectional study. BMJ Open 2014:4:e005002.

17. Knowler WC, Barrett-Connor E, Fowler SE, et al., Diabetes Prevention Program Research Group. Reduction in the incidence of type 2 diabetes with lifestyle intervention or metformin. N Engl J Med 2002;346:393-403.

18. Eddy DM, Schlessinger L, Kahn R. Clinical outcomes and cost-effectiveness of strategies for managing people at high risk for diabetes. Ann Intern Med 2005;143:251-64.

19. Stefan N, Fritsche A, Schick F, et al. Phenotypes of prediabetes and stratification of cardiometabolic risk. Lancet Diabetes Endocrinol 2016;4:789-98.

20. Pan XR, Li GW, Hu YH, et al. Effects of diet and exercise in preventing NIDDM in people with impaired glucose tolerance: the Da Qing IGT and Diabetes Study. Diabetes Care 1997:20:537-44.

21. Boulé NG, Haddad E, Kenny GP, et al. Effects of exercise on glycemic control and body mass in type 2 diabetes mellitus: a meta-analysis of controlled clinical trials. JAMA 2001;286:1218-27.

22. Sigal RJ, Kenny GP, Wasserman DH, et al. Physical activity/ exercise and type 2 diabetes: a consensus statement from the American Diabetes Association. Diabetes Care 2006;29:1433-8.

23. Johnson PA, Fulp RS. Racial and ethnic disparities in coronary heart disease in women: prevention, treatment, and needed interventions. Womens Health Issues Off Publ Jacobs Inst Womens Health 2002;12:252-71.

24. Belza B, Walwick J, Shiu-Thornton S, et al. Older adult perspectives on physical activity and exercise: voices from multiple cultures. Prev Chronic Dis 2004;1:A09.

25. Lawton J, Ahmad N, Hanna L, et al. "I can't do any serious exercise': barriers to physical activity amongst people of Pakistani and Indian origin with Type 2 diabetes. Health Educ Res 2006;21:43-54.

26. Caperchione CM, Kolt GS, Mummery WK. Physical activity in culturally and linguistically diverse migrant groups to Western society: a review of barriers, enablers and experiences. Sports Med Auckl NZ 2009;39:167-77.

27. Dogra S, Meisner BA, Ardern Cl. Variation in mode of physical activity by ethnicity and time since immigration: a cross-sectional analysis. Int J Behav Nutr Phys Act 2010;7:75.

28. Creatore MI, Moineddin R, Booth G, et al. Age- and sex-related prevalence of diabetes mellitus among immigrants to Ontario, Canada. CMAJ 2010;182:781-9.

29. Behavioral Risk Factor Surveillance System (BRFSS). U.S. Chronic Disease Indicators (CDI) Dataset. Centers for Disease Control and Prevention (CDC), 2013.

30. Karter AJ, Schillinger D, Adams AS, et al. Elevated rates of diabetes in Pacific Islanders and Asian subgroups: the Diabetes Study of Northern California (DISTANCE). Diabetes Care 2013;36:574-9.

31. Nguyen TH, Nguyen TN, Fischer T, et al. Type 2 diabetes among Asian Americans: prevalence and prevention. World J Diabetes 2015;6:543-7.

32. Choi SE, Chow VH, Chung SJ, et al. Do risk factors explain the increased prevalence of type 2 diabetes among California Asian adults? J Immigr Minor Health 2011;13:803-8. 